\title{
Fertility in Islamic Republic of Iran: Levels, Trends and Differentials during Three Decades (1967-1996)
}

\author{
Kazem Mohammad \\ Department of Epidemiology and Biostatistics \\ School of Public Health \\ Tehran, Iran
}

Farideh Khalaj Abadi Farahani

National Research Center of Medical Sciences

Tehran, Iran

Mehdi Rahgozar

Welfare and Rehabilitation University

Tehran, Iran

Mahmood Mahmoodi Farahani

Department of Epidemiology and Biostatistics

School of Public Health

Tehran, Iran

\begin{abstract}
:
This study focuses on the fertility levels and trends of Iranian women aged 1049 years during three decades, 1967-1996. Information was collected by interviewing a systematic cluster sample of 13,253 households. The basic date of concern was the date of each live born child for a sample of women in reproductive age and whether the live born was alive at the time of the study. The detailed nature of these data collected for each birth enabled fertility rates to be calculated for exact periods before the survey, for exact calendar years. Higher fertility rates were found for the period 10-15 and 15-20 years preceding the survey. These high fertility levels are probably due to some socio-economic changes in favor of higher level of fertility immediately after the 1979 revolution. However the results of the present survey show during 1967-1996, the TFR ${ }^{1}$ had dropped from 6.38 to 2.88 (an expected TFR based on fertility behavior during 1992-96). This decline was probably due to delay in marriage and policy changes in favor of population control particularly since 1987 . Despite this potential fertility decline in recent years, Iran is expected to face a baby boom as the offspring who were born during the 1976-86 reach to the reproductive age in the coming decades.
\end{abstract}

Key Words: Fertility history, fertility trend, fertility level, Iran 
Kazem Mohammed, Farideh Khalaj Abadi Farahani, Mehdi Rahgozar and Mahmood Mahmoodi Farahani

\section{Résumé:}

This study focuses on the fertility levels and trends of Iranian women aged 1049 years during three decades, 1967-1996. Information was collected by interviewing a systematic cluster sample of 13,253 households. The basic date of concern was the date of each live born child for a sample of women in reproductive age and whether the live born was alive at the time of the study. The detailed nature of these data collected for each birth enabled fertility rates to be calculated for exact periods before the survey, for exact calendar years. Higher fertility rates were found for the period 10-15 and 15-20 years preceding the survey. These high fertility levels are probably due to some socio-economic changes in favor of higher level of fertility immediately after the 1979 revolution. However the results of the present survey show during 1967-1996, the TFR $^{1}$ had dropped from 6.38 to 2.88 (an expected TFR based on fertility behavior during 1992-96). This decline was probably due to delay in marriage and policy changes in favor of population control particularly since 1987 . Despite this potential fertility decline in recent years, Iran is expected to face a baby boom as the offspring who were born during the 1976-86 reach to the reproductive age in the coming decades.

Key Words: Fertility history, fertility trend, fertility level, Iran

\section{Introduction}

One of the most important events of the twentieth century has been the demographic transition. All developed and many developing societies have experienced dramatic changes in their birth rates (Brass w; Juarez $f$ and Scott A., 1997). The dramatic decline in the Iranian fertility rate during the past three decades is well known, and recent fertility trends in the Islamic Republic of Iran reveals the value of family planning programs (Aghajanian et al, 1999). Five population censuses have been conducted in Iran every 10 years from 1956 to 1996 .The average annual population growth rate in the two censuses of 1976 and 1986 was reported to be $2.7 \%$ and $3.2 \%$, respectively, which has shown an increase of $0.5 \%$. This increase in population growth rate was brought about by a dramatic decline in mortality, particularly between 1981 and 1986, a higher birth rate, and the influx of refugees, e.g., Afghans and Iraqis. In the first ten years after the revolution in 1979, the population growth rate was increased unprecedented. Thus, the government decided to reduce the rapid population growth rate in 1987 by taking some new policies in population control. As the trend of TFR according to censuses from 1974 to 1996 reveals a sharp decline especially after 1988. TFR in 1974, 1985, 1988, 1995 and 1996 were reported 6, 5.6, 5.2, 2.8 and 2.6, respectively. (Country report of population, 1999; Shadpoor, 1993) 
The 1979 revolution and the subsequent establishment of the Islamic Republic marked a dramatic turning point in the country's social history. Among the policies that were changed at that time was that of birth control, which was denounced and abandoned by the revolutionary government. In addition, the new government strongly supported early marriage and the traditional view that refused contraception and use of birth control methods.

The lack of government interest in controlling population growth during 197986 continued until 1989 when a new period of reconstruction emerged. In the 1990 s, a period of social and economic changes occurred with the implementation of the first and second cultural, social and economic plans. This period was accompanied by a great improvement in public health and the establishment of a family planning program, particularly in rural areas. (Aghajanian et al, 1999).

Several demographic, economic and political factors have been suggested to relate to the fertility changes in each period. Whether this rapid population growth rate in the specific period (1976-86) is due to a decline in mortality rate accompanied by a constant fertility, or is actually merely due to over or under enumeration in these 3 decades (1967-1996) is still a matter of debate.

In 1975, Brass suggested that retrospective surveys in which birth histories were recorded might be the most promising means for the detection of fertility trends in population with inadequate data of traditional type. This approach could be more reliable than the obvious proposal of repeated surveys to determine fertility levels at intervals of a few years (Brass, 1975; Brass and Rashad, 1992). In Iran there is a series of surveys on fertility and its trend, by traditional measures, but the tracing of fertility trends by traditional measures in the early stages of a demographic transition is speculative and uncertain even if the data are of good quality, when the data are subject to significant reporting errors, the difficulties are exaggerated greatly (Brass W, Juarez F and Scott A., 1997), Thus, it is no surprise that there is a controversy about the nature and indeed existence of a declining trend in fertility in Iran and due to varying biases of traditional measures it seems it is difficult to draw a precise conclusions about fertility trends.

Hence, The present survey has been proposed to determine fertility levels and trends during 3 decades preceding the survey (1967-96) by a new technical approach to interpret more clearly the modification of the reproductive behavior. In fact, it deals with two main questions:

1. What are the fertility levels and trends by time periods as well as by cohort, during 1967-96? 
Kazem Mohammed, Farideh Khalaj Abadi Farahani, Mehdi Rahgozar and Mahmood Mahmoodi Farahani

2. If any changes have occurred, are these confined to any specific subgroup of the population?

The answer to these questions is essential for an understanding of the fertility behavior of the population and alternative interpretation of trends in parity progression and also recognision of the contribution of fertility behavior changes during 1967-96 in population transition in Iran.

\section{Data and Methodology}

Information was collected by a systematic cluster sample of 13,253 households. The data source was 1 per 1000 of total households and each cluster included 14 households. The household survey collected data on basic demographic variables such as family size, age, educational level and marital status of women aged 10-49 years resident in the household. From amongst these households, 11,116 unmarried women aged 10-49 years and 10,908 women aged 10-49 years who were already married at least once were identified and were successfully interviewed. The individual questionnaire of ever married women aged 10-49 years collected detailed data on their fertility histories including, number of their pregnancies, number of live birth and stillbirth, age of mother at each live birth and stillbirth, date of birth of each live birth and still birth, type of each delivery, birth attendant of each delivery.

The detailed nature of the data collected for each birth enabled fertility rates to be calculated for exact periods before the survey, for exact calendar years. Rates obtained from births in the past years are compared with expected births based on current pregnancies. This provides an additional check on the reliability of the pattern of fertility but not on the level. The average number of total births and first birth per woman in 5-year periods for cohorts aged 15-19 to 45-49 at the survey and cumulative rates over age for each period are shown in Table 6 and Table 7 , respectively.

In the present survey, the Brass Model (1975) has been applied for estimation. In this model, the basic date of concern are the date and order of births of each live born child for the sample of women in the reproductive period, according to the current ages of women. The cohort marker in this study denotes birth cohort (age of women). The cohort marker is divided into seven five-year classes determined by age at interview. Total birth for each cohort of women is allocated to different periods preceding the survey date (5 -year periods were used here). Reading along the rows gives the births of cohorts of women in a period preceding the survey as they moved from one age group to the next. Reading down the column gives the birth to different cohorts in the same time intervals preceding the survey. (See Tables 6 and 7). Downward diagonals from the left show the births to women from different cohorts over the same age changes. If the original data report accurately, a reliable picture of current 
Fertility in Islamic Republic of Iran: Levels, Trends and Differentials during Three Decades (1967-1996)

fertility and its variation over time will be achieved, hence a draft of women's reproductive level and it's trend in the preceding decades will be determined.

\section{Results}

The mean family size in urban, rural and total sample was 4.76, 5.49 and 5.04, respectively. Approximately, $8.5 \%$ of households had a family size of 9 or more and family size in rural areas is more than 2 fold $(13.3 \%)$ in comparison with urban areas (5.6\%) (Table 1). The age distribution of women aged 10-49 years by region reveals that population of rural is younger than urban areas (Table 2). The results reveal that only $1 \%$ of women aged $45-49$ years have never married. Among 21,893 women aged 10-49 years, 50.8\% haven't got married at the time of the survey, $47.9 \%$ were married and $1.3 \%$ of them were widowed or divorced. The highest proportion of married women belongs to age groups; 35 39 and 40-44 (92.1\%) (Table 3).

Table 1

Family Size by Region, Islamic Republic of Iran: 1996

\begin{tabular}{|c|c|c|c|c|c|c|}
\hline \multirow{2}{*}{$\begin{array}{c}\text { Family } \\
\text { Size }\end{array}$} & \multicolumn{2}{|c|}{ Urban } & \multicolumn{2}{|c|}{ Rural } & \multicolumn{2}{|c|}{ Total } \\
\hline & $\#$ & $\%$ & \# & $\%$ & $\#$ & $\%$ \\
\hline 1 & 276 & 3.2 & 195 & 3.7 & 471 & 3.4 \\
\hline 2 & 891 & 10.4 & 519 & 9.9 & 1410 & 10.3 \\
\hline 3 & 1450 & 17.0 & 646 & 12.2 & 2096 & 15.2 \\
\hline 4 & 1688 & 19.8 & 692 & 13.2 & 2380 & 17.3 \\
\hline 5 & 1421 & 16.6 & 727 & 13.9 & 2148 & 15.6 \\
\hline 6 & 1138 & 13.3 & 685 & 13.1 & 1823 & 13.2 \\
\hline 7 & 763 & 8.9 & 583 & 11.2 & 1346 & 9.8 \\
\hline 8 & 433 & 5.2 & 484 & 9.3 & 917 & 6.7 \\
\hline $9+$ & 476 & 5.6 & 693 & 13.3 & 1169 & 8.5 \\
\hline Total & 8536 & 100.0 & 5224 & 100.0 & 13760 & 100.0 \\
\hline Mean & \multicolumn{2}{|c|}{4.76} & \multicolumn{2}{|c|}{5.49} & \multicolumn{2}{|c|}{5.04} \\
\hline
\end{tabular}


Kazem Mohammed, Farideh Khalaj Abadi Farahani, Mehdi Rahgozar and Mahmood Mahmoodi Farahani

Table 2

Age Distribution of Women Aged 10-49 Years by Region Islamic Republic of Iran: 1996

\begin{tabular}{ccccccc}
\hline \multirow{2}{*}{$\begin{array}{c}\text { Age } \\
\text { Group }\end{array}$} & \multicolumn{2}{c}{ Urban } & \multicolumn{2}{c}{ Rural } & \multicolumn{2}{c}{ Total } \\
& $\#$ & \% & $\#$ & \% & $\#$ & \% \\
\hline & & & & & & \\
$10-14$ & 2776 & 20.8 & 2008 & 23.1 & 4784 & 21.7 \\
$15-19$ & 2762 & 20.7 & 1934 & 22.2 & 4696 & 21.3 \\
$20-24$ & 1912 & 14.4 & 1381 & 15.9 & 3293 & 15.0 \\
$25-29$ & 1601 & 12.0 & 1008 & 11.6 & 2609 & 11.9 \\
$30-34$ & 1347 & 10.1 & 753 & 8.7 & 2100 & 9.5 \\
$35-39$ & 1329 & 10.0 & 701 & 8.1 & 2030 & 9.2 \\
$40-44$ & 1015 & 7.6 & 563 & 6.5 & 1578 & 7.2 \\
$45-49$ & 591 & 4.4 & 341 & 3.9 & 932 & 4.2 \\
& & & & & & \\
Total & 13333 & 100.0 & 8689 & 100.0 & 22022 & 100.0 \\
& & & & & & \\
\hline
\end{tabular}

Table 3

Marital Status of Women Aged 10-49 Years by Age Groups Islamic Republic of Iran: 1996

\begin{tabular}{|c|c|c|c|c|c|c|c|c|}
\hline \multirow[t]{2}{*}{$\begin{array}{c}\text { Age } \\
\text { Group }\end{array}$} & \multicolumn{2}{|c|}{$\begin{array}{c}\text { Never } \\
\text { Married }\end{array}$} & \multicolumn{2}{|c|}{$\begin{array}{l}\text { Divorced or } \\
\text { Widowed }\end{array}$} & \multicolumn{2}{|c|}{ Married } & \multicolumn{2}{|c|}{ Total } \\
\hline & $\#$ & $\%$ & $\#$ & $\%$ & $\#$ & $\%$ & $\#$ & $\%$ \\
\hline $10-14$ & 4761 & 99.5 & -- & -- & 23 & 0.5 & 4784 & 100.0 \\
\hline $15-19$ & 4036 & 85.0 & 10 & 0.2 & 649 & 13.8 & 4695 & 100.0 \\
\hline $20-24$ & 1578 & 47.9 & 26 & 0.8 & 1690 & 51.3 & 3294 & 100.0 \\
\hline $25-29$ & 484 & 18.6 & 53 & 2.0 & 2071 & 79.4 & 2608 & 100.0 \\
\hline $30-34$ & 151 & 7.2 & 52 & 2.5 & 1897 & 90.3 & 2100 & 100.0 \\
\hline $35-39$ & 72 & 3.5 & 88 & 4.3 & 1871 & 92.1 & 2031 & 100.0 \\
\hline $40-44$ & 25 & 1.6 & 100 & 6.3 & 1452 & 92.1 & 1577 & 100.0 \\
\hline $45-49$ & 9 & 1.0 & 82 & 8.8 & 840 & 90.2 & 931 & 100.0 \\
\hline Total & 11116 & 50.8 & 284 & 1.3 & 10493 & 47.9 & 21893 & 100.0 \\
\hline
\end{tabular}


Fertility in Islamic Republic of Iran: Levels, Trends and Differentials during Three Decades (1967-1996)

Illiteracy is shown to increase with age. In contrast, younger women are more likely to be more educated than older women. 57.9\% of women aged 15-19 years had studied up to secondary level or more in comparison with $11.2 \%$ in women aged 45-49 years. Overall, illiteracy among married women in all age groups was likely to be increased when compared to all women. This may be due to marriage in young ages which prohibit continuing education in women (Tables 4 and 5).

Examination of the uncumulated rates (reading down the diagonals from left to right to compare rates for the same ages in Table 6) reveals higher rates for the period 10-15 years before the survey (1982-86) for women aged $25+$ at the time of the survey (1.519) than for rates at the same ages but occurring in other periods, Also, there is a higher rate for the period 15-20 years before the survey (1977-81) for women aged 20+ at the time of the survey (1.325), than for rates at the same ages but occurring in other periods. In other words, for women aged $20+$, there is evidence of an increase of births in the period 15-20 years before the survey (1977-81) (Figure 1). Furthermore, for women aged 30-34, there is evidence of increase of birth rate (1.477) in the period 15-20 years before the survey (1977-81). Leaving aside the value for the cohort aged 35-39; rates at age 20-24 show a steady decline over time from 1.260(25-29 years before the survey, 1967-71) to 0.529 in the most recent 5- year period (1992-96).

Examination of the number of births in the right part of Table 6 (mean children ever born for cohort up to age group) reveals a decline in birth amongst women younger than 35 years at the time of the study up to each age group. For instance, the number of births in women aged 35-39 years up to the age of 20 has been 1.729, while among women aged 30-34, 25-29 and 20-24 were 1.588, 1.238 and 0.697 , respectively. Hence, there is some evidence of declining and delaying in childbearing amongst younger generations. Examination of the uncumulated rates (reading down the diagonal from left to right to compare rates for the same ages in Table 7) reveals higher rates for first birth for the period 2530 years before the survey (1967-71) for women aged 15-19(0.253) and it shows a higher rates for the period 15-20 years (1977-81) and 25-30 years before the survey (1967-71) for women aged 20-24(0.479 and 0.480, respectively) (Figures 1 and 2).

\section{Discussion}

According to the results of the present survey, with some approximating most of age groups have had higher birth rates for the period 10-15 and 15-20 years before the survey (1982-86 and 1977-81) than for rates at the same ages but occurring in other periods. Moreover, birth rates at most age groups show a steady decline over time since 1967 to 1996 , except the period of 10-15 years and 15-20 years before the survey (1977-81 and 1982-86). 


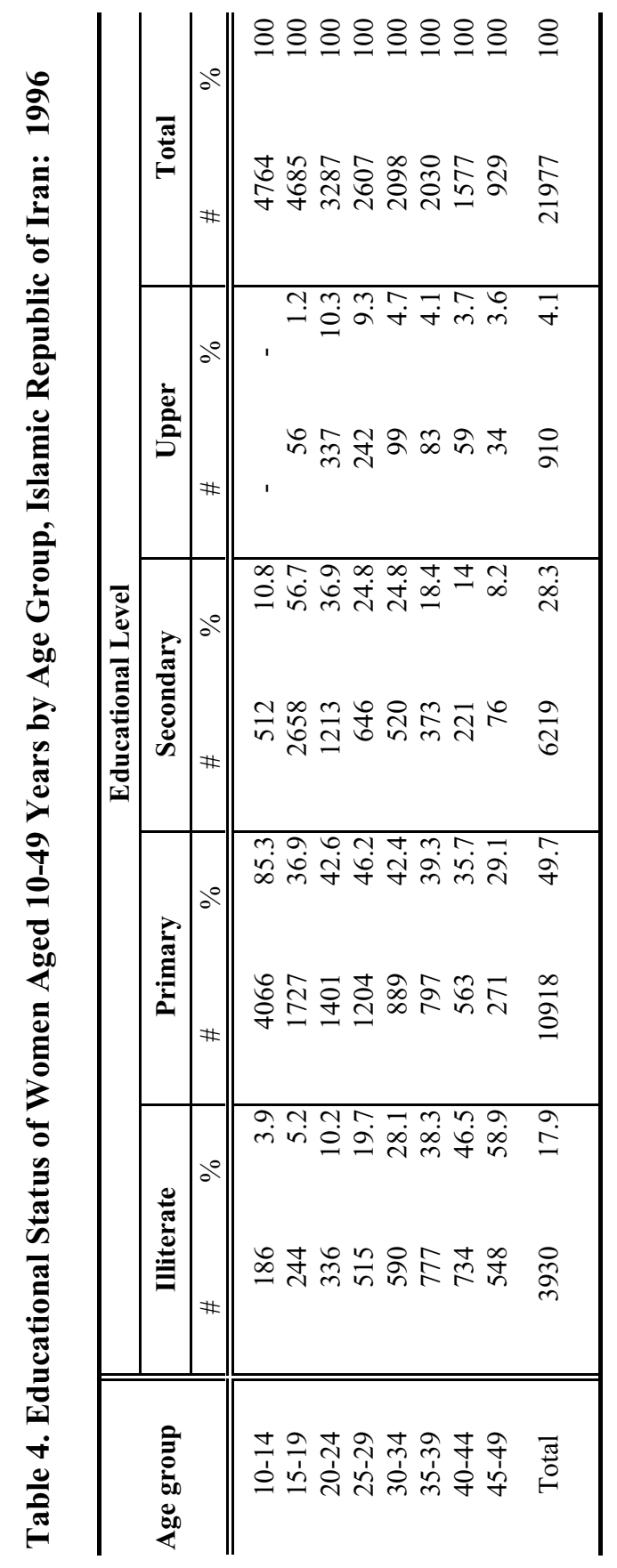




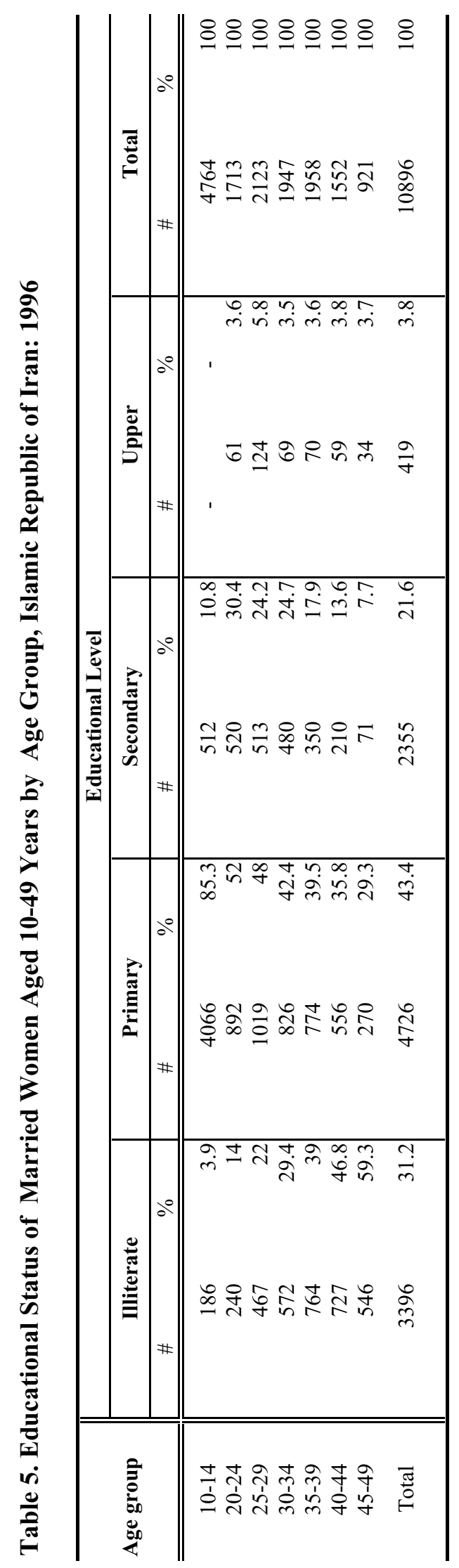


Table 6

The Number of Births per Woman and the Cumulated Rates for Cohorts and Periods

Number of births per woman by current age and period of occurrence

\begin{tabular}{|c|c|c|c|c|c|c|c|c|}
\hline Current Age & 1992-1996 & $1987-1991$ & 1982-1986 & $1977-1981$ & $1972-1976$ & $1967-1971$ & 1962-1966 & $1957-1961$ \\
\hline $15-19$ & 0.079 & 0.001 & & & & & & \\
\hline $20-24$ & 0.529 & 0.166 & 0.002 & & & & & \\
\hline $25-29$ & 0.772 & 0.905 & 0.323 & 0.010 & & & & \\
\hline $30-34$ & 0.667 & 1.185 & 1.212 & 0.367 & 0.009 & & & \\
\hline $35-39$ & 0.441 & 1.068 & 1.519 & 1.325 & 0.390 & 0.011 & & \\
\hline $40-44$ & 0.273 & 0.868 & 1.367 & 1.514 & 1.202 & 0.381 & 0.008 & \\
\hline $45-49$ & 0.121 & 0.623 & 1.124 & 1.477 & 1.481 & 1.26 & 0.282 & 0.008 \\
\hline
\end{tabular}

Mean children ever born for cohort up to age groups

\begin{tabular}{l||rllllll}
\hline & $15-$ & $20-$ & $25-$ & $30-$ & $35-$ & $40-$ & $45-$ \\
\hline \hline $15-$ & 0.080 & & & & & & \\
$20-$ & 0.168 & 0.697 & & & & & \\
$25-$ & 0.333 & 1.238 & 2.010 & & & & \\
$30-$ & 0.376 & 1.588 & 2.773 & 3.440 & & & \\
$35-$ & 0.401 & 1.729 & 3.248 & 4.316 & 4.757 & & \\
$40-$ & 0.389 & 1.591 & 3.105 & 4.472 & 5.340 & 5.613 & \\
$45-$ & 0.290 & 1.550 & 3.031 & 4.508 & 5.632 & 6.255 & 6.376 \\
\hline
\end{tabular}

Cumulated births per woman for corresponding to age groups at the end of period

\begin{tabular}{l||cccccccc}
\hline & $1992-1996$ & $1987-1991$ & $1982-1986$ & $1977-1981$ & $1972-1976$ & $1967-1971$ & $1962-1966$ & $1957-1961$ \\
\hline \hline $15-$ & 0.079 & 0.167 & 0.325 & 0.377 & 0.399 & 0.392 & 0.290 & 0.008 \\
$20-$ & 0.608 & 1.072 & 1.537 & 1.702 & 1.601 & 1.652 & & \\
$25-$ & 1.380 & 2.257 & 3.056 & 3.216 & 3.082 & & & \\
$30-$ & 2.047 & 3.325 & 4.423 & 4.693 & & & & \\
$35-$ & 2.488 & 4.193 & 5.547 & & & & & \\
$40-$ & 2.761 & 4.816 & & & & & & \\
$45-$ & 2.882 & & & & & & & \\
\hline
\end{tabular}



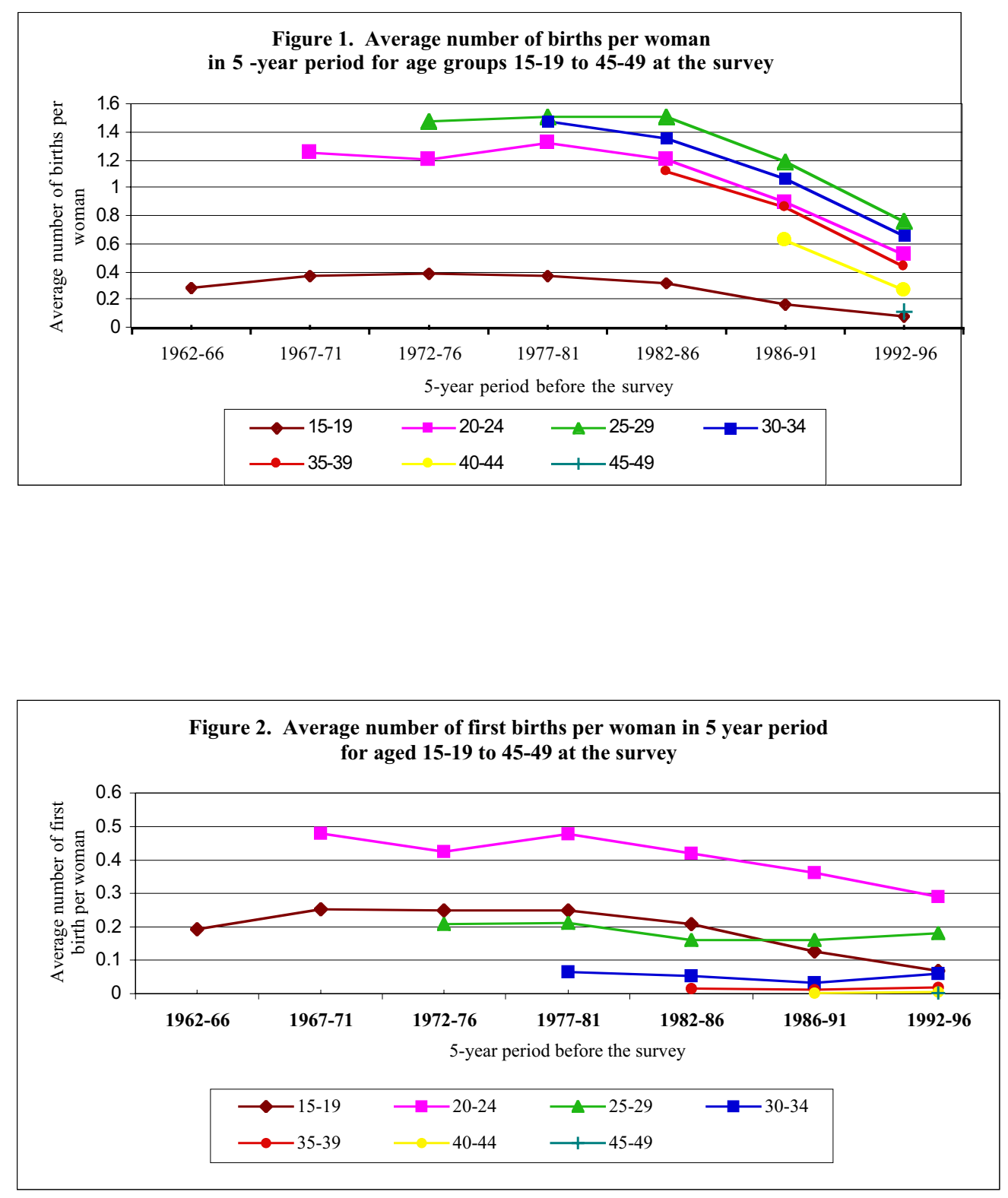
Kazem Mohammed, Farideh Khalaj Abadi Farahani, Mehdi Rahgozar and Mahmood Mahmoodi Farahani

From 1967 to 1976, Iran experienced a decline in population growth rate, with an average of $2.7 \%$ while the annual rate during the preceding decades was 3.1 $\%$. The trend of decline in the population growth rate reflects a lowering of the birth rate. Indeed, the estimated crude birth rate decreased from 49 live births per thousand in 1966 to 42.7 per thousand in 1976 . This fertility decline was the outcome of three main demographic factors, including delaying in marriage, decline in the proportion of women married and decline in age-specific fertility. Reduction of marital fertility was one of the most important factors since the proportion of women married for all women aged 15-49 decreased from $81 \%$ in 1966 to $75 \%$ in 1976 , hence the number of women who were exposed to fertility decreased (Aghajanian et al, 1999). A study in China has also shown that marriage in early age leads to early childbearing and high fertility rate (Cheng, 1993).

Age -specific fertility rates declined for all women between the ages of 20 and 40, while TFR dropped from 7.7 children per women to 6.3. This fertility decline is likely at least in part due to former government policies during the period 1966-1976 including granting women the right to vote, the political participation and placing women in high official posts and promotion of their participation in the government organized literacy programs.

During 1976 to 1986, the downward trend in fertility was reversed and the rate of population growth once again accelerated dramatically (Aghajanian et al, 1999). The increase in birth rate from 1977 to 1986 has been shown in Table 6. Two factors can explain this reversal of the downward trend in the rate of natural increase in population growth: a decline in the crude death rate and an increase in the crude birth rate. In fact, changes in population growth could not be attributed to a lower crude death rate because of Iran-Iraq war started immediately after the revolution and most of medical attention shifted away from general population to focus on military needs. Therefore it must have been the result of an increase in births. An increase in birth rate has been shown in most age groups during 1976-1986 (Table 6). Aghajanian (1999) has also estimated an increase in crude birth rate from 42.7 per thousand in 1976 to 47.6 per thousand in 1986.

The same three demographic factors that were used previously to explain the changes in the crude birth rate could be considered in relation to fertility change in the period 1976-1986. Immediately after the Islamic Revolution of Iran (1977-81), women aged 20-24 has shown an increase in their average first birth in comparison to other age groups (Table 7). This may be due to increasing of proportion married and encouraging to bring first child immediately after marriage. However, The mean age of marriage for women in 1986 remained unchanged from the 1976 level. The proportion of women aged 15-49 who was married continued to decrease during the period but at a much slower pace than before. Some studies have shown that age at first marriage has a direct effect on fertility behavior. (Davis et al, 1956; Coale, 1971). Early marriage leading to a 
Table 7

The Number of First Births per Woman and the Cumulated Rates for Cohorts and Periods

Number of first births per woman

\begin{tabular}{|c|c|c|c|c|c|c|c|c|}
\hline Current Age & $1992-1996$ & $1987-1991$ & 1982-1986 & $1977-1981$ & $1972-1976$ & $1967-1971$ & 1962-1966 & $1957-1961$ \\
\hline $15-19$ & 0.069 & 0.002 & & & & & & \\
\hline $20-24$ & 0.290 & 0.126 & 0.003 & & & & & \\
\hline $25-29$ & 0.181 & 0.363 & 0.209 & 0.009 & & & & \\
\hline $30-34$ & 0.060 & 0.160 & 0.421 & 0.249 & 0.009 & & & \\
\hline $35-39$ & 0.018 & 0.033 & 0.161 & 0.479 & 0.250 & 0.007 & & \\
\hline $40-44$ & 0.005 & 0.012 & 0.053 & 0.212 & 0.426 & 0.253 & 0.008 & \\
\hline $45-49$ & 0.002 & 0.002 & 0.015 & 0.065 & 0.209 & 0.480 & 0.194 & 0.008 \\
\hline \multicolumn{9}{|c|}{ Cumulated rates per cohort up to ages } \\
\hline & $15-$ & $20-$ & $25-$ & $30-$ & $35-$ & $40-$ & $45-$ & \\
\hline $15-$ & 0.071 & & & & & & & \\
\hline $20-$ & 0.129 & 0.419 & & & & & & \\
\hline $25-$ & 0.218 & 0.581 & 0.762 & & & & & \\
\hline $30-$ & 0.258 & 0.679 & 0.839 & 0.899 & & & & \\
\hline $35-$ & 0.257 & 0.736 & 0.897 & 0.930 & 0.948 & & & \\
\hline $40-$ & 0.261 & 0.687 & 0.899 & 0.952 & 0.964 & 0.965 & & \\
\hline $45-$ & 0.202 & 0.682 & 0.891 & 0.956 & 0.971 & 0.973 & 0.975 & \\
\hline \multicolumn{9}{|c|}{ Cumulated rates per period up to ages } \\
\hline & 1992-1996 & 1987-1991 & 1982-1986 & $1977-1981$ & $1972-1976$ & $1967-1971$ & $1962-1966$ & $1957-1961$ \\
\hline $15-$ & 0.069 & 0.128 & 0.212 & 0.258 & 0.259 & 0.260 & 0.202 & 0.008 \\
\hline $20-$ & 0.359 & 0.491 & 0.633 & 0.737 & 0.685 & 0.740 & & \\
\hline $25-$ & 0.540 & 0.651 & 0.794 & 0.949 & 0.894 & & & \\
\hline $30-$ & 0.600 & 0.684 & 0.847 & 1.014 & & & & \\
\hline $35-$ & 0.618 & 0.696 & 0.862 & & & & & \\
\hline $40-$ & 0.623 & 0.698 & & & & & & \\
\hline $45-$ & 0.625 & & & & & & & \\
\hline
\end{tabular}


Kazem Mohammed, Farideh Khalaj Abadi Farahani, Mehdi Rahgozar and Mahmood Mahmoodi Farahani

high fertility rate (Hirschman, 1985). Since 1970, Asia has experienced a trend towards later age at marriage. In all Asian countries, except most of those in south Asia, the female mean age at marriage is over 20 years. (Xenos et al, 1992). Furthermore, Some studies in Pakistan revealed that fertility decline in Pakistan in recent years was partly due to rising age of marriage. Some of these studies emphasized that relationship of age at marriage and fertility can be very misleading. The group of women who delay their marriage are very selective on many of the important socio-economic characteristics including education, residence and work participation and can not be taken to be representative of population behavior as a whole. (Booth $\mathrm{H}$ et al, 1980). In 1979, some factors created a favorable political environment for a higher level of fertility during the early years after revolution. Firstly, the family planning program did not have very much support among religious groups. Therefore, immediately after the revolution, the program was shut down by the Islamic government as a signal of its lack of interest in population policy. Moreover, the changing roles of the sexes caused by revolution and the Iran-Iraq war immediately after revolution created an environment that encouraged having more children.

During the period 1986-96, birth rates at almost all age groups reveals a steady decline over time with a sharp decline over the period 1991-96, The annual population growth rate declined from $3.8 \%$ in 1986 to $1.5 \%$ in 1996 . This decreasing trend in population growth rate suggests a decline of birth rate. Indeed, the estimated crude birth rate declined from 48 per thousand in 1986 to 38 per thousand in 1991 and It continued to decline in urban and rural population $28 \%$ and $27 \%$, respectively. On the other hand, increased age at marriage led to changes in the proportion married and declining trend in exposure to fertility affected changes in birth rate during 1986-96. There was a $13.3 \%$ increase in age at marriage from 1986 (19.8 to 1996 (22.4). The proportion of currently married women decreased from 72 per cent in 1986 to 67 percent in 1996 for all women aged 15-49. Declining in age-specific fertility rate was the main factor in declining birth rate during the 1986-96 (Aghajanian et al, 1999). A National Health Survey (NHS) in Iran in 1991, revealed a delay in age at first pregnancy during 1981-91 and the delay in the first pregnancy can be due to delaying in first marriage. (Mohammad, 1997).

The present study shows that TFR for women aged 45-49, based on their past fertility behavior was 6.38 while based on their fertility behavior during 199196, it has reduced to less than half (2.88). A similar result has been shown through a population and family health survey in Jordan in 1997, TFR at the time of the survey was 4.4, which was $40 \%$ lower than the rate recorded in 1976 (7.4) (Jordan population and family planning survey, 1997).

Dabbaghi has estimated crude birth rates and TFR in Iran for the years 1987 up to 1996. Dabbaghi estimated a TFR of 2.27 in 1996 which is approximately compatible with the TFR (2.88) derived from the current study in 1996 (an expected TFR based on fertility behavior during 1991-96). (Statistical Center of 
Fertility in Islamic Republic of Iran: Levels, Trends and Differentials during Three Decades (1967-1996)

Iran, 1991; Nasehi, 1997; Dabbaghi, 1998). Establishment of family planning program by the Iranian government during this period, and also changes which led to socio-structural precursors for fertility decline and motivation for smaller family size and policy changes by the government regarding population control during this period assisted fertility decline. As a consequence of the effective delivery of family planning services started in 1989, the overall contraceptive prevalence rate in urban and rural areas became about 80 and 65 percent in 1997, respectively. While these rates were about $54 \%$ and $20 \%$ in 1976 , respectively. (Aghajanian et al, 1999). Improvement of child survival during 1986-96, which has contributed to less demand for childbearing, and hence a declining in total fertility rate is considered another significant factor. Between 1976 and 1991, infant mortality decreased from 112 per thousand live births to 63.2 infant death per thousand births (Statistical yearbook of Iran, 1994).

Cleland J. et al, (1997) suggested that it is most unlikely that fertility transition in developing countries would have occurred without massive prior mortality decline. It should be noticed that fertility decline has spread to almost all developing countries within a 50 year span suggests that there must be some common underlying cause. Mortality decline is proposed as that common cause. Essentially, fertility decline is no more than a delaying response to the huge increase in survival probabilities (Cleland J, In Press). Community development project in rural areas in Iran, which have brought electricity and sanitary water supplies to rural households and also developing the network of rural health workers or Behvars are also considered as another factor for improving the environment for child survival and declining fertility in 1986-96. In 1986, about $52 \%$ of the households had access to piped water while it was $21.5 \%$ in 1976 . By 1996, this percentage had increased to $71 \%$, similarly the rate of access to electricity in their home increased from $14 \%$ in 1976 to $66 \%$ in 1986 and $88 \%$ in 1996. The role of women's educational attainment in relation to fertility decline is well known. As the education rises among females, the idea of working outside the home becomes more and more prevalent and this is another reason toward smaller family size. In 1975, the literacy rate for Iranian female six years and older was 35.5 percent (Aghajanian, 1994), while by $1996,74 \%$ of female aged six years and older were literate (SCI, 1998). The importance of educational level on fertility was also revealed by Kirk and Pillet in a study on 23 countries in sub-Saharan Africa in 1998. The results showed that fertility rate and number of children decreased by increasing of educational level of women (D Kirk et al, 1998).

The increasing cost of child rearing and economic crisis during 1986-96 and policy changes introduced by the government in supporting Family Planning programs through providing free contraceptive in primary health care system all seems to have profound influence on fertility decline.

The present survey has revealed that after the period of 1977-81, women aged 15-19 years and 20-24 years have had a declining trend in their first birth. This 
Kazem Mohammed, Farideh Khalaj Abadi Farahani, Mehdi Rahgozar and Mahmood Mahmoodi Farahani

declining trend in first birth has not been shown among women aged 25-29, 3034 and 35-39 years. This delay in bringing first child can be the result of improvement of women education and their involvement in community activities more than before and it fact encouraged women to postpone their childbearing.

\section{Conclusion}

The fertility rate in Iran seems to continue declining especially if the population control policies continue with a strong support. Despite this potential fertility decline, in the next 2-3 decades, continued rapid population growth in Iran is inescapable because of youthful age structure of the population which is the outcome of the increase in birth rate during 1976-86. Beyond that point much depends on fertility trends in the coming decades. This continued population growth may exacerbate greatly problems of underemployment, while the prognosis for future fertility decline is better, hence this fact demonstrate the appeal for provision of appropriate family planning services for this population and anticipation of increasing fertility rate in coming years in order to to make suitable social, economical and populational planning.

\section{Acknowledgments:}

This study has been carried out in the National Research Center of Medical Sciences and has been supported by Management and Planning Organization, United Nations Population Fund (through project \#IRA/95/po6), Deputy Ministry of Research and Technology and Deputy Ministry of Health (Ministry of Health and Medical Education).

We appreciate and acknowledge Ministry of Health and Medical Education, United Nation Population Fund, Deputy Ministry of Health, Deputy Ministry of Research \& Technology, Management and Planning Organization. Also, we appreciate Dr. Mohsen Naghavi and Dr. Fahimeh Ramezani Tehrani and Ms Mahnaz Heidari Seraj.

\section{End Notes:}

1. TFR is the sum of the age-specific fertility rate, it represents the average number of children a woman would have at the end of her reproductive years if she were subject to the observed age-specific rates. 


\section{References:}

Aghajanian, A., Mehryar A. H. 1999. "Fertility transition in the Islamic Republic of Iran," Asia- Pacific Population Journal, 14(1): 21-42.

Booth, H., Iqbal Alam, 1980. "Fertility in Pakistan: Levels, trends and differentials," World Health Fertility Survey Conference, No. 9, Background Paper, No.1, $7^{\text {th }}$ to $11^{\text {th }}$ July.

Brass, W., Juarez, F. and Scott, A. 1997. “ An analysis of parity-dependent fertility falls in tropical Africa," in G. Jones, R. Douglas, J. Caldwell, R. D'souza (eds.), The Continuing Demographic Transition. Oxford: Claredon Press.

Brass, W., 1975. "Methods for Estimating Fertility and Mortality from Limited and Defective Data," Chapel Hill. North Carolina: Laboratories for Population Statistics.

Brass, W., Rashad H., 1992. "Exploratory demographic analysis of imperfect maternity histories to determine levels and trends of fertility," The Analysis of Maternity Histories to Determine levels and Trends in Fertility. Liege: IUSSP Ordinary Edition.

Cheng, C. Z., 1993. "The fertility decline in China: The contribution of changes in marital status and marital fertility," Asia-Pacific Population Journal, $1(2): 1-14$

Coale, A., 1971. “Age pattern of marriage,” Population Studies, 25(2): 193214.

Cleland, J., "Restating the obvious: the effects of improved survival on fertility," Population and Development Review, in press.

Davis, Kingsley and Judith Blake, 1956. " Social Structure and Fertility: an analytic framework," Economic Development and Cultural Change, 4(3): 211-235.

Dabbaghi, F., 1998 (dissertation). Islamic Azad University of Iran

Kerk, D. and Pillet, B., 1998. "Fertility levels, trends and differentials in subSaharan Africa in the 1980s and 1990s," Studies in Family Planning, 1-23.

Hirschman, Charles, 1985. "Pre-marital socio-economic roles and the timing of family formation: A comparative study of 5 Asian societies," Demography, 22(1): 35-59. 
Kazem Mohammed, Farideh Khalaj Abadi Farahani, Mehdi Rahgozar and Mahmood Mahmoodi Farahani

Jordan Population and Family Health Survey, 1997.

Mohammad, K., 1997. "Trend of first marriage age and age at first pregnancy among women aged 15-49 years according to program of health and disease," Hakim Journal, period 2, No.3.

Nasehi, M. E, 1997, Seminar of assessing socio-economic indicators of Iran.

Population, 1999. "Reproductive Health and Family Planning, Iran," Country Report of Population Programs.

Shadpoor, K., 1993. Primary Health Care in Iran, Ministry of Health and Medical Education and UNICEF,

Statistical Center of Iran, Measuring Population Growth Rate of Iran, 19731976.

Statistical Center of Iran, 1991, Management of Socio-economic Statistics, Vital Indicators of Provinces of the Country in 1986.

Statistical Yearbook of Iran, 1994, Tehran, Statistical Center of Iran.

Xenos, Socorro. A, Galliano, 1992, "Trends in female and male age at marriage and celibacy in Asia," Papers of the program on population. East West Center, Program on population, No. 120. 